\title{
A atuação do psicólogo hospitalar frente aos familiares do paciente com morte iminente
}

\author{
The performance of the hospital psychologist against family members of patients with imminent \\ death
}

Letícia Sobreira Cezário ${ }^{\dagger}$, Juliana Fernandes de Souza Ribeiro ${ }^{*^{*}}$

Como citar esse artigo. Cezário, L.S;

Ribeiro, J.F.S. A atuação do psicólogo

hospitalar frente aos familiares do

paciente com morte iminente. Revista

Mosaico - 2019 Jul/Dez.; 10 (2): 40-47

\begin{abstract}
Resumo
O presente trabalho demonstra como a morte está presente em diferentes culturas e momentos históricos, ressaltando que a forma de encará-la está associada a crenças, rituais e religiões. A família diante da terminalidade pode sofrer desajustes no que diz respeito a sua estrutura física, econômica e emocional. A vivência do luto antes ou após a morte de um familiar pode ser perpassada em diferentes etapas do luto: negação, raiva, barganha, depressão e aceitação. $\mathrm{O}$ trabalho procura destacar a importância da atuação do psicólogo junto aos familiares do paciente em situação de morte iminente que visa promover o acolhimento do sofrimento desses familiares, em um cenário em que muitas vezes, apenas o paciente é priorizado. O artigo exemplifica a vivência da morte na família através do filme "Uma prova de amor" de Nick Cassavetes, apresentando uma articulação da teoria em um contexto prático onde toda família de forma direta e/ou indireta é afetada pelo adoecimento grave de um entequerido.

Palavras-chave: Família, Morte, Psicologia.
\end{abstract}

\begin{abstract}
The present article demonstrates how death is present in different cultures and historical moments, emphasizing that the way of facing it is associated with beliefs, rituals and religions. The family in the face of terminality may suffer mismatches regarding its physical, economic and emotional structure. The experience of mourning before or after the death of a relative can be traced back to different stages of mourning: denial, anger, bargaining, depression, and acceptance. This work aims to highlight the importance of the psychologist's performance with the relatives of the patient in a situation of imminent death, aiming to promote the reception of the suffering of these relatives, in a scenario in which only the patient is often prioritized. The article exemplifies the experience of death in the family through Nick Cassavetes's film "My Sister's Keeper", presenting a articulation of theory in a practical context where every family in a direct and/or indirect way is affected by the serious illness of a loved one.

Keywords: Family, Death, Psychology.
\end{abstract}

\section{Introdução}

O presente artigo tem por finalidade ressaltar a importância da atuação do psicólogo hospitalar junto aos familiares de pacientes com morte iminente, discorrendo questões que envolvem o aspecto cultural da morte em diferentes momentos históricos e as fases do luto que são enfrentadas pelos familiares e pacientes graves.

Em um primeiro momento vê-se a morte como algo que perpassa pelo aspecto cultural e o contexto histórico relacionado a rituais, crenças e religião. Logo após há a descriçãodo processo enfrentado pelos familiares do paciente com morte iminente. Em sequência, desenvolve-se a questão do luto iminente que inicia-se ao descobrir a doença grave, relacionando as fases que antecedem a morte. E posteriormente, faz- se a articulação da teoria apresentada no decorrer do trabalho com o filme "Uma prova de amor" de Nick Cassavetes.

A morte é uma fase do desenvolvimento humano, semelhante ao nascimento, porém o morrer nem sempre é encarado como algo simplesmente natural. Há uma necessidade de distanciamento deste termo, que para muitos é visto como algo sombrio e pavoroso, se remetendo apenas a aspectos negativos.

O termo "morte" não se refere apenas ao fim da vida, mas pode estar associado a mortes subjetivas; como a perda de um emprego, a frustração de um sonho que envolve questões semelhantes como o "luto", o sofrimento.

De acordo com Combinato e Queiroz (2006 apud QUEIROZ; SOUZA; PONTES, 2012) quando se fala de morte, em cada tempo e cultura existe um significado atribuído a ela. Inicialmente, esse significado é externo

Afiliação dos autores: †Graduanda, curso de Psicologia, Universidade de Vassouras, RJ, Brasil;

† Mestre em Ensino de Ciências da Saúde, Docente na Universidade de Vassouras, RJ, Brasil.

Email para correspondência: julianafdesouza@yahoo.com.br 
ao indivíduo, pertencendo à cultura. À medida que esse é internalizado, transforma-se em um instrumento subjetivo da relação do indivíduo consigo mesmo. Assim, o significado extrínseco adquire um sentido pessoal para o indivíduo.

Para elaborar o presente trabalho foi feita uma pesquisa bibliográfica tendo Maria Júlia Kovacs, Elizabeth Kuber-Ross, Mayla Cosmo Monteiro, Elza Queli Valduga, Verena Augustin Hoch como autores de refêrencia.

\section{A Morte Na Sociedade}

A morte é um acontecimento de muita importância que é encarado de diversas maneiras em diferentes culturas. Embora cada pessoa lide com ela de um jeito peculiar, a questão cultural passada também de geração a geração influencia na forma de vivenciar esse momento de finitude de vida. Segundo MatosSilva (2011), a importância da morte transparece na mobilização que a morte gera envolvendo emoções, crenças, rituais e outros comportamentos relacionados a morte variando a partir da cultura de cada sociedade. Muitas transformações ocorreram na forma de lidar com a morte ao longo da história e essas mudanças tem como base cada momento histórico, porém tais alterações foram lentas e quase imperceptíveis para os que as vivenciaram.

Ariès (1977 apud MATOS-SILVA, 2011) agrupa os modos de se conceber a morte em quatro períodos distintos na história do Ocidente. São eles:

- A morte domada - No período entre os séculos $\mathrm{V}$ e XI, a morte era vista de forma próxima e familiar, enfrentada mais tranquilamente pelo fato de ser entendida como algo natural e que era precedida pela ressurreição de todos. Essa certeza de que a vida continuaria após a morte fazia com que ela fosse aceita com tranquilidade, embora houvesse a dor pela perda ela era sentida de forma suportável. Devido a proximidade e familiaridade, Ariès chamou este período de "morte domada".

- A morte de si mesmo - Nos séculos XI e XII a individualidade de cada sujeito passa a ser observada e as atitudes tomadas por este no decorrer de sua vida, influenciavam no que aconteceria com o indivíduo após a sua morte. As pessoas que em vida praticaram boas ações eram consideradas justas e dignas da ressurreição, já as que praticavam as más eram consideradas malditas e não tinham direito a salvação. Alicerçado nesta ideia surgiram dúvidas a respeito da salvação e logo o temor da morte. Não era qualquer morte que trazia temor, mas sim a própria morte. Este período estendeu-se até o século XVIII e trouxe modificações também quanto a questão do luto, que deveria ser externado quando houvesse visita de parentes e amigos, de forma a mostrar a dor e o sofrimento vividos pela perda de alguém importante.

- A morte do outro - Até o século XVIII a ideia de família consistia apenas em interesses políticos e econômicos, a contar desta época então o romantismo começou a ser inserido e os casamentos eram formados através de sentimentos e afeições, o que outrora não importava. A morte de um ente querido passou a ser algo difícil e inaceitável desde a inserção de famílias construídas com base nos sentimentos. Assim, temia-se a morte do outro e não mais a própria morte. A questão do luto passou a ser externada de forma ainda maisintensa e exagerada, independente da ocasião, envolvendo choros, desmaios, jejuns, mostrando assim a dificuldade de lidar com a morte do outro nesse contexto. A saudade fez com que fossem criados hábitos de se homenagear os mortos e preservar suas memórias.

- A morte interdita - No século XX os sentimentos e a familiaridade intensificaram. $\mathrm{O}$ sofrimento surgia a partir da perspectiva de perder alguém próximo, pois a morte estava associada a doenças, agonias e desesperos. Então, criou-se a ideia de que o melhor a ser feito era ocultar do "moribundo" e dos familiares a possibilidade de morte, para que ambos não sofressem com o seu real estado e com proximidade da morte. Neste período, os cuidados que antes eram feitos em casa foram transferidos para o hospital com intenção de amenizar o sofrimento dos familiares e amigos. Muitas modificações a respeito da morte ocorreram. O luto acontecia de maneira mais discreta, sem muitas demonstrações as crianças quase não eram envolvidas nesse contexto. Essas proibições de manifestação de sentimentos e comunicações sobre a morte compreendem esse período de morte interdita denominado por Ariès.

E em consequência das transformações sociais ocorridas ao longo dos quinze séculos mencionados por Ariès, várias concepções sobre a morte surgiram gerando diferentes rituais e formas de lidar com a mesma.

Falar de morte envolve inevitavelmente a vida, mas uma interrupção da vida, colocando à prova a qualidade desta, que mesmo com tanta tecnologia desenvolvida atualmente, ainda passa pelo processo de sua finalização. $\mathrm{O}$ avanço da medicina com novos remédios como os antibióticos, vacinas e quimioterapia mais eficazes são utilizados para tentar prolongar a vida e com isso, muitas doenças já foram eliminadas e outras oferecem menos riscos do que antes, mas não descartam a possibilidade da morte. (KOVACS, 2005)

$\mathrm{O}$ medo e pavor de encarar a morte perpetuam em muitas gerações e isso tem gerado algumas consequências na forma de lidar com esta. Um exemplo que pode ser abordado é o fato das famílias optarem por preservar as crianças de notícias referentes a morte de um ente querido. Porém, afastá-las deste momento pode fazer com que elas vivam suas dores sozinhas, pois as pessoas querem impedi-las do sofrimento e não dão a oportunidade de viver o luto compartilhado participando 
das conversas e discussões sobre os medos e temores trazidos por aquela situação de morte e morrer. Todo esse medo apresenta uma sociedade em que a morte é encarada como um "tabu", fazendo com que as crianças sejam poupadas da morte com a omissão dos fatos e que o doente, muitas vezes, não saiba o real quadro em que se encontra. "Quanto mais avançamos na ciência, mais parece que tememos e negamos a realidade da morte". (KÜBLER-ROSS, 2017, p.11)

Com tantos fatores envolvidos na omissão da morte, esta era vista como um ato solitário e impessoal. A maior parte dos moribundoseramlevados aos hospitais e cuidadospor médicos e enfermeiros longe de suas famílias, distante assim do conforto do seu lar. Dentro dos hospitais, o paciente muitas vezes correspondia a um número, um prontuário, não tendo direito de opinar e externar seus desejos em meio atantos procedimentos queinvadiam o seu corpo e ele não podia sequer reagir.

Atualmente estes cenários de morte solitária e impessoal dentro dos hospitais vem se modificando. Embora muitas práticas antigas ainda se perpetuem, hoje já existe uma valorização do paciente como alguém que tem sentimentos, necessitando do apoio de familiares e amigos no momento da hospitalização e morte. O doente não é visto apenas como um número ou prontuário, e sim como alguém que mesmo à beira da morte ainda tem vida, tendo suas questões que serem consideradas tanto pela equipe médica quanto pelos familiares.

\section{A Família Diante Da Terminalidade}

\section{Para Carter e McGoldrick:}

\begin{abstract}
A família é definida como um sistema aberto, em transformação, intercomunicante, que forma um conjunto de padrões por meio dos quais os seus membros interagem e regulam o seu comportamento, ou seja, é formada por pessoas que são produtos e produtoras de seu contexto social, cultural e emocional. (1995 apud MONTEIRO, 2017, p.64)
\end{abstract}

Com o adoecimento e a hospitalização de um dos membros da família o núcleo familiar que é composto por leis e regras internas sofre um desequilíbrio e há a necessidade de uma reorganização por causa dos impactos trazidos pela internação. $\mathrm{O}$ familiar cuidador pode vir a sentir-se isolado já que a vida de todos os outros continua, enquanto a sua rotina deixa de existir, passando a vivenciar a rotina de um hospital. Além disso, surgirem despesas extraordinárias para custo e manutenção nas proximidades do hospital e/ou custeio do tratamento.

O sofrimento que envolve a perda está diretamente relacionado ao vínculo que se tem com a pessoa. Quando há um membro da família hospitalizado em situação de morte iminente o contexto familiar é alterado significativamente. É necessária a dedicação quase que de forma integral de membros da família que irão se responsabilizar por aquele paciente que, em maior número, não se encontra em condições de responder por si. Estes cuidadores familiares geralmente deixam vários aspectos da sua vida em pausa, passando mais tempo no hospital do que em casa. Podem até mesmo enfrentar dificuldades financeiras por abandono do emprego em muitas situações. Todas essas questões podem trazer ansiedade, depressão, distúrbio de apetite esono, além de isolamento social e afetivo.

Os familiares, embora sejam importantes no processo de hospitalização do paciente, não são aconselhados a se entregarem de forma integral por conta da hospitalização do familiar. Kübler-Ross (2017) acredita que seja bom para o paciente ver que sua família não se desestruturou definitivamente por causa de sua internação. "Como o paciente em fase terminal não pode encarar a morte o tempo todo, o membro da famílianão pode, nem deve, excluir todas as outras interações para ficar exclusivamente ao lado do paciente." (KÜBLERROSS, 2017, p.165)

Quando chega a notícia do estado grave e da iminente morte do familiar, os problemas se tornam ainda mais complexos, pois envolvem uma série de questões que estão relacionadas a comunicação ou não daquele fato ao doente e uma preocupação em encontrar um culpado por deixar que o familiar esteja vivendo um estado tão crítico. Segundo Kübler-Ross (2017), a culpa talvez seja a companheira mais dolorosa da morte, pois quando o paciente é diagnosticado com uma doença fatal, os familiares tendem a se culpar por isso levantando questões como: "Eu deveria ter notado a mudança mais cedo encorajando-o a buscar ajuda logo [...] Se ao menos eu o tivesse mandado ir ao médico antes." (KÜBLER-ROSS, 2017, p. 167)

A forma como o paciente e seus familiares lidam com o adoecimento, a hospitalização e a morte em si podem variar de acordo com as crenças e o contexto cultural de cada família. Os momentos que precedem a morte podem ser vividos de forma intensa pelo paciente, mas também por seus familiares.

\section{O Luto Iminente}

O luto surge a partir da perda e é considerado como uma tristeza intensa e subjetiva, pois é vivido por cada indivíduo de uma forma que está sempre articulada aos valores, crenças e até mesmo a sociedade pertencente.

Kahn (2016) diz que quando gostamos de alguém ou de algo investimos grande quantidade de energia psíquica (libido) neste objeto, no relacionamento com ele e nas memórias advindas deste. Quando perdemos este objeto, passamos a investir o amor que tínhamos por ele em nós mesmos para que este futuramente seja 
direcionado a outro.

O luto refere-se à forma como é processada a perda vivenciada individualmente ou no contexto familiar. De acordo com Delalibera (2015), um bom funcionamento familiar envolvendo uma boa comunicação e coesão entre os membros da família corroboram para que a vivência do luto seja potencializada de maneira que todos os integrantes da família estejam saudáveis psicologicamente. Poisquandonãoháum funcionamento eficaz da família, geralmente a resposta adaptativa a situação de perda é prejudicada e o período de morte iminente enfrentado pela família torna-se mais penoso.

Fonseca (2004 apud FRANCO, 2010) diz que o processo de luto pode ter início no momento em que se recebe um diagnóstico de uma doença fatal ou potencialmente assim pelas perdas que essediagnóstico causa no meio familiar. Essas perdas podem estar relacionadas à segurança, funções vitais, independência e imagem corporal. Segundo a autora, antes mesmo do diagnóstico fechado a família já enfrenta um processo de sofrimento que envolve dores, exames, desgastes emocionais e físicos, o que ela chama de luto antecipatório, melhor definido como a possibilidade de elaboração do luto a partir do adoecimento.

O envolvimento da família nesse processo de adoecimento é visto por Franco (2010) em algumas fases que são: crise, crônica e final:

- Crise: esta fase acontece antes do fechamento de um diagnóstico, quando a família percebe que há algo de errado com um dos seus membros e começa a fazer interpretações dos sintomas com bases culturais e religiosas. Geralmente essas interpretações, frequentemente baseadas nos sintomas, envolvem riscos que amedrontam a família e o doente.

- Crônica: Na fase crônica conclui-se que não há como viver de forma "normal" com tantas "anormalidades" relacionadas ao quadro do doente. As crises tornam-se mais agudas e a família encontra muitas dificuldades de lidar com as não potencialidades e perda de identidade do familiar adoecido. Porém, mesmo com tantas adversidades a família faz de tudo para equilibrar as necessidades dela e os cuidados que o moribundo precisa.

- Final: esta fase compreende a morte iminente. Neste momento está claro para todos que a morte é inevitável e geralmente é o momento em que há muitas dificuldades em lidar com a separação e o luto. Além de resolução de questões pendentes, dar assistência aos últimos desejos do doente, a despedida. Esta etapa abrange dificuldades tanto para o paciente quanto para $\mathrm{o}$ cuidador, também a família e a equipe profissional que trabalha com este paciente.

A autora Kübler-Ross (2017) apresenta fases que antecedem a morte que podem ser vivenciadas pelos pacientes e familiares, sendo: negação, raiva, barganha, depressão e aceitação. Segundo a autora, nem todos os pacientes e familiares necessariamente passam por todas as fases e não há uma ordem pré-estabelecida para cada uma delas, pois podem oscilar.

A primeira fase geralmente é a negação, ela se dá geralmente após a informação do diagnóstico. Segundo Mendes, Lustosa e Andrade (2009) quase todos os pacientes passam pela negação total ou parcial, tentando negar a realidade própria ou do seu familiar.

As autoras afirmam que a negação funciona como uma defesa ao ego, onde o paciente nega a possibilidade de morte para lutar pela vida. Embora possa auxiliar alguns pacientes a terem mais motivação pela vida, esta fase pode interferir de forma negativa no prognóstico, quando estes resolvem não procurar auxílio médico, pois não acreditam no diagnóstico recebido. "A negação funciona como um para-choque depois de notícias inesperadas e chocantes, deixando que o paciente se recupere com o tempo, mobilizando outras medidas menos radicais."(KÜBLER-ROSS, 2017, p. 44)

A raiva é uma fase comum aos pacientes, mas também pode acontecer com familiar cuidador. Nela surgem sentimentos de ira, revolta e ressentimento: "por que eu?". Segundo Kübler-Ross (2017) torna-se mais difícil lidar com o paciente, pois a raiva se propaga em todas as direções, projetando-se no ambiente sem "razão plausível".Para entender a razão dessa raiva basta colocar-se no lugar do doente ou do cuidador e verá que sua raiva é devida aos projetos inacabados, a vida seguindo e ele dentro de um hospital com poucas possibilidades de vida. Mendes, Lustosa e Andrade (2009) salientam que é importante procurar saber qual a origem da raiva do paciente tendo a convicção que em grande parte essa não é endereçada a alguém especifico.

A barganha é uma fase em que pacientes e familiares oferecem a alguém superior um acordo a fim de postergar a inevitável morte. Geralmente a barganha é feita com Deus, confessada a capelães ou outros lideres religiosos, onde o paciente ou familiar promete ter uma vida dedicada a Deus caso receba a cura.

A depressão surge quando o indivíduo reconhece que a doença de fato existe e que com ela vem uma série de limitações físicas, emocionais e até financeiras. As dificuldades do tratamento e hospitalização prolongados aumentam a tristeza que aliada a outros sentimentos, ocasionam a depressão. De acordo com Mendes, Lustosa e Andrade (2009) quando o paciente exterioriza o seu pesar a aceitação da situação difícil em que se encontra torna-se mais fácil.

A aceitação acontece com pacientes que não tiveram uma morte rápida e é o momento em que a família e o paciente aceitam o diagnóstico e a possibilidade de morte deixando de lado a depressão e a raiva.

Vale ressaltar que as cinco fases descritas por Kübler-Ross (2017) não acontecem uma única vez com cada paciente ou familiar, podendo a mesma fase ser vivida em diversos momentos. 
Segundo Franco (2010), o luto não é doença e nem todo enlutado precisa submeter-se à psicoterapia, porém deve-se analisar as condições em que a família enlutada se encontra, compreendendo seu luto, levando em consideração suas crenças e sua cultura de modo geral. "Portanto nunca será demais ressaltar que os discursos sobre a morte e o luto refletem nossa ideologia que, por sua vez, busca expressão para os valores da cultura." (FRANCO, 2010, p.13)

\section{A Atuação Do Psicólogo Junto Aos Familiares Do Paciente Em Fase Terminal}

$\mathrm{O}$ adoecimento e todas as suas etapas trazem conflitos internos e externos ao paciente e a toda família envolvida. O processo de descoberta do diagnóstico, internação, prognóstico, alteração nas atividades cotidianas devido à rotina hospitalarinfluenciam em uma desestrutura familiar observada até na praticidade, no que diz respeito a todos os afazeres da casa, alimentação, trabalho e finanças também influenciam de forma emocional (interrupção de atividades, falta de lazer, medos e incertezas). Sobre isto, Valduga e Hoch (2012) dizem:

Cuidar de uma paciente em fase terminal causa ônus significativo ao cuidador e à sua família. Há uma sobrecarga estafante e estressora em relação a essa atividade diária e ininterrupta de cuidados. Este ônus ocorre tanto em nível físico quanto psíquico, social e financeiro. (VALDUGA e HOCH, 2012, p.18)

Soares (2007) afirma que é de suma importância que haja um cuidado com os familiares dos pacientes, pois eles são essenciais no desenvolvimento global do paciente que muitas vezes encontra-se muito limitado. E segundo o autor, o período de internação traz uma carga excessiva de estresse, distúrbio de humor e ansiedade que pode persistir até após a morte do paciente.

É muito importante que a família do mesmo também receba a devida atenção no ambiente hospitalar, pois uma família bem estruturada pode ser muito útil na recuperação do ente querido. Mendes, Lustosa e Andrade (2009) afirmam:

Se não se levar em conta a família do paciente em fase terminal, não se pode ajudá-los eficazmente. No processo da doença, os familiares desempenham papel preponderante, e suas reações muito contribuem para a própria reação do paciente.(MENDES,LUSTOSAEANDRADE, 2009,p. 166)

Pereira e Dias (2007 apud VALDUGA e $\mathrm{HOCH}$, 2012) realizaram um estudo sobre "O familiar cuidador do paciente terminal: o processo de despedida no contexto hospitalar" e concluíram que devido ao sofrimento pela morte iminente do ente querido, o acompanhamento de um psicólogo ao familiar cuidador torna-se de extrema importância para que este possa elaborar o luto de forma eficaz.

Ressaltamos que, o luto pode vir antes mesmo da morte de alguém próximo e as fases desse luto precisamser acompanhadas para que tanto o paciente quanto o familiar possam lidar com essa situação da melhor forma. De acordo com Kübler-Ross (2017), se os familiares se dispusessem a compartilhar esses sentimentos que surgem nos diferentes estágios, conseguiriamenfrentar aos poucos a realidade de separação eminente da pessoa querida e chegarem juntos à aceitação.

Muitas vezes a falta de comunicação entre equipe e familiares faz com que surjam muitas inquietações a respeito do quadro do paciente como: "Será que ele sente muita dor? Será que ele vai sair daqui? O que posso fazer para ajudá-lo?" Todas essas questões podem trazer ao familiar cuidador sentimentos de angústia, de inutilidade que só são amenizados diante de um esclarecimento da equipe profissional responsável por aquele paciente.

O auxílio de um psicólogo também se faz necessário para que a família saiba colaborar com o paciente considerando seus desejos e suas questões. Em algumas situações é difícil para os familiares compreenderem o desejo do paciente de morrer logo para que a dor cesse, pois aparenta uma atitude covarde e de omissão da vida.

Quando o paciente decide falar sobre o seu funeral, especificando o que deseja que aconteça, a família tende a esquivar-se negando essa possibilidade. $\mathrm{O}$ desejo de morrer em casa também pode trazer grandes incômodos, pois é doloroso pensar em ver um ente querido morrendo dia após dia dentro de casa, sentindo dores, aparentando que a família não lhe presta cuidados e não teve a atitude de se submeter a recursos hospitalares. Essas situações trazem sentimentos de impotência a família que nada mais pode fazer por quem tanto ama.

Carter e McGoldrick (1995, p. 404, apud VALDUGA e HOCH, 2012) citam: "Cada remissão traz a esperança de vida, e cada exacerbação o medo da morte" que causa um esgotamento emocional na família, pois ver uma pessoa querida morrendo com dor e estar impotente frente a isso, torna -se algo massacrante e difícil de lidar.

Neste cenário todo voltado para o doente, a atuação do psicólogo frente aos familiares dos pacientes terminais é essencial. É importantíssimo oferecer escuta a esses dando voz aos que só podem ouvir sobre o quadro do seu ente querido e quase não podem questionar diante dos saberes médicos, e assim possibilitar um espaço para que estes relatem seus anseios, suas inquietações, 
dúvidas e angústias. Sobre isto Domingues (2013) ressalta:

O campo de trabalho do psicólogo são as palavras e a observação. Ele fala, escuta e observa. Escuta ainda mais do que fala. Não é algo tão simples, pois o ato de escutar, falar e também captar signos com valor de palavras pode levar o paciente a mudanças em seu quadro de bem estar. (DOMINGUES, 2013, p. 15)

É importante que o psicólogo esteja atento ao contexto familiar, à forma como lidam com a doença, seja no momento anterior, durante ou posterior a morte do paciente. Na fase inicial da doença ele pode esclarecer dúvidas sobre o tratamento, orientar sobre a importância de estar ali e auxiliar na fase de adaptação à doença e a hospitalização. No decorrer da doença, ouvir os desabafos sobre a rotina exaustiva e a ambiguidade em relação a vida do paciente, pois ora quer que o paciente lute pela vida, ora deseja que ele morra logo para que todo esse sofrimento termine. E na fase final oferecer a oportunidade de estarem juntos ao paciente, mesmo que ele esteja em coma. Após a morte dar-lhes a chance de estar com o corpo, tocar, despedir-se da forma que quiserem. Podendo o psicólogo atuar até mesmo após o sepultamento, pois é a fase mais difícil para o familiar cuidador. Segundo Domingues (2013), para os familiares do paciente que acaba de falecer, os momentos que sucedem ao período de sepultamento são tomados geralmente por sentimentos de dor, perda, solidão, culpa, entre outros.

Portanto, cabe ao psicólogo:

- Acolher, dando vez e voz a estes familiares com intervenções que se dão de forma a conhecer o contexto familiar;

- Minimizar os agentes estressores e geradores de ansiedade;

- Avaliar como a família lida com a doença e possibilidade de morte do ente querido;

- Facilitar expressões de sentimentos e emoções;

- Investigar os recursos de enfrentamento;

- Intermediar relações com a equipe a fim de promover confiança na equipe e nas decisões por ela tomadas;

- Orientar sobre reações emocionais frente ao paciente adoecido;

- Facilitar rituais de despedida;

- Auxiliar na reestruturação familiar no pósmorte.

Todas estas intervenções junto às famílias podem ser realizadas de forma individual ou coletiva. As atividades em grupo são de extrema importância, pois através dela os familiares conhecem outras pessoas que estão vivendo situações similares ou ainda mais difíceis que as suas; e o contato com esses que partilham da mesma dor fortalece, permite troca de experiências de tratamentos que deram certo, estabelece vínculos, impede o isolamento social e tudo isso auxiliando então no processo de enfrentamento da morte iminente de alguém próximo.

\section{"Uma Prova De Amor" A Vivên- cia Da Morte Na Família}

O filme "Uma prova de amor" relata a história de Kate e de sua família. Kate é uma adolescente portadora de leucemia e sua mãe dedica-se a sua cura de forma integral desde a descoberta de seu adoecimento. Para os pais de Kate, o descobrimento da doença não foi nada simples, pelo contrário, eles sofreram muito com a informação do diagnóstico de sua filha ainda pequena. A mãe de Kate, sua principal cuidadora, deixou o emprego e todos os outros afazeres que não envolvessem Kate; já o pai manteve o seu trabalho secular, porém também se dedicava muito a filha doente. $\mathrm{O}$ irmão um pouco mais velho veio a sofrer com as consequências da doença de Kate, pois passou a ser menos assistido pelos pais. Sempre em busca da cura da filha os pais de Kate resolveram ter um filho geneticamente planejado para que pudesse ser doador compatível à Kate. Assim nasce Ana, que desde muito nova era submetida a vários procedimentos para beneficiar a irmã. Muitas coisas mudaram quandoKate adoeceu, pois à família que era comum insere-se uma rotina de hospital, remédios, internações e mudança na vida de todos. "Tudo era bem mais fácil quando eles eram apenas crianças." (UMA Prova de amor, 2009.)

No contexto do filme é possível observar claramente as fases definidas por Franco (2010) como: crise, crônica e final.

O momento de crise precede ao diagnóstico clínico, porém nesta fase já está instalada na família uma preocupação que se dá devido aos primeiros sintomas. $\mathrm{Na}$ narrativa do filme esta fase começa quando Kate acorda com uma mancha de sangue nas costas e os pais começam a buscar por respostas àquele sintoma que nunca tinha sido apresentado pela menina. As primeiras cenas envolvem várias visitas a especialistas e o temor vivido pelos pais que aguardavam uma notícia que poderia ser ruim ou muito ruim se tratando do adoecimento da filha.

A fase crônica acontece quando o paciente e os familiares começam a reconhecer que em meio a tantas anormalidades trazidas pela doença, já não é mais possível viver como antes. Na história de Kate, quando é dado o diagnóstico de leucemia o cenário familiar muda de forma radical. Kate já não era mais a mesma, os procedimentos traziam reações negativas ao seu organismo e toda a família estava envolvida, dedicando-se de forma intensa a cuidar da menina e buscar pela sua cura. E além da leucemia, acrescenta-se 
ao quadro o diagnóstico de insuficiência renal, a partir daí os cuidados e tratamentos se intensificam e a família fica ainda mais distante de uma vida "normal".

A etapa final é o momento em que a morte está próxima e que os cuidadores e o paciente compreendem que nada mais pode ser feito. No filme é possível perceber esta fase com o agravamento do quadro clínico de Kate e as inúmeras dificuldades encontradas pela família para lidar com a aproximação da morte da menina. Dia após dia eles percebiam que os tratamentos não eram mais eficazes diante da gravidade do caso e embora percebessem o sofrimento de Kate, não se viam preparados para lidar com a separação, o luto e a possibilidade de realizar os últimos desejos dela.

Articulado as fases descritas por Franco (2010) pode-se associar as fases da morte desenvolvidas pela autora Kübler-Ross (2017), sendo: negação, raiva, barganha, depressão e aceitação.

Uma das cenas do filme em que é possível observar um exemplo de negação, se dá após o recebimento da notícia do agravamento do diagnóstico de Kate. Diante de todas as complicações a mãe se negava a crer que não havia mais nada a fazer, mesmo após o parecer negativo dado pelos médicos responsáveis pelo caso, ela ainda acreditava que a cirurgia era o melhor a ser feito. Naquele momento a mãe não suportava pensar que a filha tão amada estava em fase terminal e negar aquela situação era o que a fazia mais forte.

Há duas cenas que mostram a externalização da raiva: Kate se tranca no quarto e faz uso de bebida alcoólica, quebra objetos do quarto, grita com a irmã que tenta abordá-la e ainda tenta cortar os pulsos, mostrando-se revoltada com a doença e a perda do namorado. Outro episódio é quando a mãe de Kate percebe que todos os familiares e o médico já estavam conformados com o quadro atual da menina e fica muito irritada brigando com todos, pois ela era a única que insistia com a realização da cirurgia e não admitia que ninguém mais acreditasse que esta cirurgia poderia solucionar o problema de Kate.

A adolescente mostra-se depressiva quando recusava a levantar-se da cama, dizendo estar feia e se sentindo um monstro. $\mathrm{O}$ choro e o desespero da menina mostram sua tristeza profunda advinda das complicações da doença.

A aceitação é vista quando Kate já cansada de tanto lutar para postergar sua morte e sabendo que ela era inevitável fez um pedido a sua irmã Ana, para que ela não aceitasse mais doar seus órgãos a ela. Kate sabia que seus pais não admitiriam isso e pediu que Ana abrisse um processo judicial pedindo sua emancipação médica. Mesmo relutante Ana acatou o pedido da irmã para que ela então pudesse descansar de todo este sofrimento. Outra cena que mostra aceitação é quando o irmão de Ana sobe no telhado, rasga o desenho que fez da irmã e joga lá de cima deixando que o mesmo seja levado pelo vento. Esta cena mostra que ele já aceitava a possibilidade da irmã partir.

Em "Uma prova de amor" é possível observar a chegada de uma morte considerada prematura e agressiva, que não se atenta a contextos sociais, familiares e econômicos, simplesmente acontecendo. Lidar com a proximidade dela não é nada fácil diante daquele contextopara os familiares e cuidadores; a família sente muito a perda, mas conseguem elaborar esse luto retomando suas vidas com a eterna lembrança de Kate.

\section{Considerações Finais}

O presente trabalho enfocou a importância de se prestar cuidados e de considerar questões pertinentes á família do paciente em situação de morte iminente.

A família diante da terminalidade de um ente querido encontra, muitas vezes, dificuldades no que diz respeito a sua estrutura física, financeira e emocional, poislidar com a morte iminente de um familiar é uma tarefa complexa. Diante disso, observa-se a necessidadeda família ser assistidatambém dentro do ambiente hospitalar, onde o foco não deve estar voltado apenas para odoente, porque há um cuidador, uma família cheia de sentimentos que também precisa ser observada, contudo para auxiliarna promoção de uma vida mais saudável e uma morte digna ao adoecido.

Aatuação do psicólogo hospitalar junto às famílias de pacientes com morte iminente pode auxiliar na forma como esses familiares vão lidar com o momento de luto, bem como prestar auxilioao doente nas fases finais de sua vida;fornecendo um atendimento humanizado que permita aos mesmos externarem suas dores e angústias, serem orientados e serem ouvidos.

\section{Referências}

DELALIBERA, Mayra et al . A dinâmica familiar no processo de luto: revisão sistemática da literatura. Ciênc. saúde coletiva, Rio de Janeiro, v. 20, n. 4, p. 1119-1134, Apr. 2015

DOMINGUES, Glaucia Regina et al . A atuação do psicólogo no tratamento de pacientes terminais e seus familiares. Psicol. hosp. (São Paulo), São Paulo, v. 11, n. 1, p. 02-24, jan. 2013

FRANCO, Maria Helena. Lutos em cuidados paliativos. Disponível em: $<$ http://www.4estacoes.com/pdf/textos_saiba_mais/luto_em_cuidados_ paliativos.pdf $>$ Acesso em: 24 jan. $201 \overline{9}$.

KAHN, Michael. Freud básico: pensamentos psicanalíticos para o século XXI. 3. Ed. Rio de Janeiro: Best Bolso, 2016.

KOVACS, Maria Júlia. Educação para a morte. Psicol. cienc. prof., Brasília, v.25,n.3, p. 484-497, 2005.

KÜBLER-ROSS, Elisabeth. Sobre a morte e o morrer. 10. ed. São Paulo: Editora WMF Martins Fontes; 2017.

MACHADO, Érica. O luto no contexto hospitalar. Disponível em: <http:// www.psicologia.pt/artigos/textos/A0878.pdf>. Acesso em: 24 jan. 2019. 
MATOS-SILVA, Mariana Santiago de. Teclando com os mortos: um estudo sobre o uso do Orkut por pessoas em luto. Tese (doutorado) Pontifícia Universidade Católica do Rio de Janeiro, Departamento de Psicologia, 2011.

MENDES, Juliana Alcaires; LUSTOSA, Maria Alice; ANDRADE, Maria Clara Mello. Paciente terminal, família e equipe de saúde. Rev. SBPH, Rio de Janeiro, v. 12, n. 1, p. 151-173, jun. 2009.

MONTEIRO, Mayla Cosmo. Nada será como antes: a família diante da iminência da morte na UTI. MONTEIRO, Mayla Cosmo. A morte e o morrer em UTI: família e equipe médica em cena. Curitiba: Appris, 2017. Cap.2, p. 61-91.

QUEIROZ, Ana Helena Araújo Bonfim; SOUZA, Ângela Maria Alves e; PONTES, Ricardo José Soares. Cuidado no final da vida: reflexões sobre a morte e o morrer. Rev. Scientia, ano 01, ed. 02, p. 192 - 395, Nov. 2012/ Jun.2013.

SOARES, Márcio. Cuidando da família de pacientes em situação de terminalidade internados na unidade de terapia intensiva. Rev. bras. ter. intensiva, São Paulo, v. 19, n. 4, p. 481-484, Dec. 2007. Disponível em: $<$ http://www.scielo.br/scielo.php?script=sci_arttext\&pid=S0103507X20070 $00400013 \& \operatorname{lng}=$ en\&nrm=iso $>$. Acesso em: 25 jan. 2019.

UMAProva de amor. Direção de Nick Cassavetes [S.1.]: Warner Bros Pictures, 2009.1 DVD (109 min).

VALDUGA, Elza Queli; HOCH, Verena Augustin. Um olhar sobre os familiares cuidadores de pacientes terminais. Unoesc \& Ciência - ACHS, Joaçaba, v. 3, n. 1, p. 15-32, jan./jun. 2012. 